\title{
Clinical aspects of TP53 gene inactivation in diffuse large B-cell lymphoma
}

\author{
Elena N. Voropaeva ${ }^{1 *}$, Tatyana I. Pospelova ${ }^{2}$, Mikhail I. Voevoda ${ }^{1,2}$, Vladimir N. Maksimov ${ }^{1,2}$, Yuriy L. Orlov ${ }^{1,3}$ \\ and Olga B. Seregina ${ }^{2}$
}

From 11th International Multiconference "Bioinformatics of Genome Regulation and StructurelSystems Biology" - BGRSISB-

2018

Novosibirsk, Russia. 20-25 August 2018

\begin{abstract}
Background: The knowledge about specific mechanisms generating TP53 dysfunction in diffuse large B-cell lymphoma is limited. The aim of the current study was to comprehensively explore TP53 gene variability resulting from somatic mutations, promoter methylation, and allelic imbalance in tumorous tissue of diffuse large B-cell lymphoma (DLBCL).

Methods: DNA samples from 74 patients with DLBCL were used. Genomic DNA was isolated from paraffin blocks of lymph nodes or from extranodal biopsies of tumors by the phenol-chloroform extraction method with guanidine. Analysis of coding sequences of the TP53 gene was based on Sanger's direct sequencing method. The methylation status of the TP53 promoter was analyzed using by methylation-specific PCR on bisulfite-converted DNA. Assessment of the detected mutations was carried out in the IARC TP53 Database and the TP53 UMD mutation database of human cancer.

Results: The mutations in regions coding for the DNA-binding domain were prevalent (95\%). In the analyzed sample of patients, codons 275, 155, 272, and 212 were hotspots of mutations in the TP53 gene. In addition, functionally significant intron mutations (IVS6-36G > C and IVS5 + 43G > T) were detected. Instances of TP53 promoter methylation were observed only in a few samples of diffuse large B-cell lymphoma tissue. Furthermore, loss of heterozygosity was revealed only in the subgroup of patients with altered status of the gene (mutations were detected in five patients and promoter methylation in one case).

Conclusions: Thus, the results suggest that there are two sequential events in the formation of diffuse large B-cell lymphoma in at least some cases. The first event is mutation or methylation of the TP53 promoter, leading to appearance of a cell with increased risk of malignant transformation. The second event is the loss of an intact allele of the gene; this change is necessary for tumorigenesis. We identified TP53 mutation patterns in a Russian cohort of patients with de novo DLBCL who were treated with R-CHOP and R-CHOP-like regimens and confirmed that TP53 mutation status is a valuable prognostic biomarker.
\end{abstract}

Keywords: TP53 gene, Diffuse large B-cell lymphoma, Methylation, Allelic imbalance, Intron mutations, Sequencing

\footnotetext{
* Correspondence: vena.81@mail.ru

${ }^{1}$ Institute of Internal and Preventive Medicine, Branch of Institute of Cytology and Genetics, Siberian Branch of Russian Academy of Sciences, Novosibirsk,

Russia

Full list of author information is available at the end of the article
}

(C) The Author(s). 2019 Open Access This article is distributed under the terms of the Creative Commons Attribution 4.0 International License (http://creativecommons.org/licenses/by/4.0/), which permits unrestricted use, distribution, and reproduction in any medium, provided you give appropriate credit to the original author(s) and the source, provide a link to the Creative Commons license, and indicate if changes were made. The Creative Commons Public Domain Dedication waiver (http://creativecommons.org/publicdomain/zero/1.0/) applies to the data made available in this article, unless otherwise stated. 


\section{Introduction}

Diffuse large B-cell lymphoma (DLBCL) is characterized by diffuse proliferation of atypical large lymphocytes containing a vesicular nucleus, prominent nucleoli, and basophilic cytoplasm. DLBCL occurs in one third of cases of non-Hodgkin's lymphoma among adults: up to $25-30 \%$ in developed countries and $30-40 \%$ in developing countries; these statistics make it one of the most frequent types of lymphoma in the world $[1,2]$.

An important mechanism underlying the development of DLBCL is the genetic instability of lymphoid cells as part of normal maturation of B cells; this instability can lead to precancerous genetic lesions. As a result, a disturbance of B-cell homeostasis with unregulated proliferation, differentiation blockage, and B-cell immortalization occurs at one of the stages of lymphoid-cell maturation [3].

Genetic factors that disrupt DNA repair or apoptosis may increase the risk of precancerous events. The lesions in the B-lymphocyte genome that had not been repaired or had not been eliminated by apoptosis may be modulated in the future by environmental influences, epigenetic factors (hypo- or hypermethylation), concomitant (autoimmune) diseases, and/or genetic polymorphism and may promote further tumorigenesis [4].

The protein p53 is a nuclear phosphoprotein playing a crucial role in rapid elimination of damaged and potentially dangerous cells [5]. Its tumor-suppressing function results from participation in such processes as cell cycle control, DNA repair, apoptosis, aging, and autophagy through transcription-dependent and -independent mechanisms [6]. Lymphocytes under stress tend to go through p53-dependent apoptosis, in contrast to other cell types, which undergo cell cycle arrest as well as p53-independent apoptosis or necrosis under stressful conditions [7]. For this reason, dysfunction of the TP53 gene is a basis for initiation and progression of lymphoproliferative disorders $[7,8]$.

An increase in genetic instability that promotes further tumor progression and allows malignant cells to escape immunosurveillance and therapeutic interventions has been observed in B lymphocytes with an inactivated TP53 gene. Acceleration of the pace of polyclonal evolution of B cells-with various genetic abnormalities, such as changes in chromosome numbers, chromosomal rearrangements, gene mutations, and amplification of some regions of the genome-takes place under conditions of p53 dysfunction [9].

Dysfunction of the p53 protein may be due to disturbances in the structure of the gene, changes in the transcription process and stability of mRNA or malfunction of post-translational modifications or of interactions of the p53 protein. Probably, molecular mechanisms involving DNA and leading to dysfunction of p53 include gene mutations, promoter methylation, allelic imbalance, and genetic polymorphism [4].

\section{Materials and methods}

The aim of this study was to comprehensively describe the frequency of promoter methylation and that of loss of heterozygosity as well as the frequency, diversity, and functional significance of mutations in coding and intron regions of the TP53 gene among patients with DLBCL in Novosibirsk, Russia.

\section{Study population}

The study population included 74 patients with DLBCL (35 men and 39 women), aged $21-78$ years $(52.8 \pm 14.3$, mean $\pm \mathrm{SD}$ ), who were admitted to Novosibirsk Hematological Center during 2012-2015. As many as 91\% of these patients had advanced (III-IV) stages of the disease and two-thirds of them had a poor prognosis according to the International Prognostic Index (IPI). All patients underwent 6-8 cycles of R-CHOP-21 and R-CHOP-like regimens. The Table 1. presents summarizing patients characteristics.

\section{Genomic DNA isolation}

Genomic DNA was isolated from paraffin blocks of lymph nodes or from extranodal biopsies of tumors by the phenol-chloroform extraction method with guanidine. The tissue sections containing at least $70-80 \%$ of tumor cells were chosen for analysis.

\section{TP53 gene sequencing and mutation analysis}

A prescreening of mutations was not performed. Analysis of coding sequences of the TP53 gene (from exon 3 to exon 10) and of adjacent intron regions was carried out by Sanger's direct sequencing method, according to the IARC protocol (2010 update) [10]. At the first stage, single fragments of DNA were produced by PCR, with the genomic DNA as a template. The obtained amplicons were desalted and cleaned up from unincorporated primers and deoxynucleotide triphosphates on microcolumns with Sephadex ${ }^{\mathrm{TM}}$ G-50 resin (GE Healthcare Bio-Sciences $\mathrm{AB}$ ).

The sequencing of samples was carried out by the method of capillary electrophoresis on a Hitachi 3500 Genetic Analyzer (Applied Biosystems) with the BigDye ${ }^{\circ}$ Terminator v.3.1 Kit (Applied Biosystems). Analysis of the sequencing results and alignment and comparison of the obtained data with a reference sequence were conducted in software packages Chromas, SeqScape v.2.7, and Sequence Scanner.

Assessment of biological significance of the detected mutations was carried out in the IARC TP53 Database and the TP53 UMD mutation database of human cancer $[11,12]$.

In addition, bioinformatic analysis of mutations was conducted in SIFT, Mut_ass and on-line program Polymorphism Phenotyping 2 (PolyPhen-2) [13]. To evaluate 
Table 1 Clinical features of DLBCL patients at the time of diagnosis $(n=74)$

\begin{tabular}{|c|c|c|c|c|}
\hline & $\begin{array}{l}\text { All group } \\
(n=74)\end{array}$ & $\begin{array}{l}\text { TP53mut } \\
(n=12)\end{array}$ & $\begin{array}{l}\text { TP53wt } \\
(n=62)\end{array}$ & $\begin{array}{l}P \text {-value } \\
\text { (TP53mut } \\
\text { vs. TP53wt) }\end{array}$ \\
\hline Mean age (yrs) & $52.8 \pm 14.3$ & $50.3 \pm 10.6$ & $58.6 \pm 18.5$ & 0.347 \\
\hline Sex & & & & 0.403 \\
\hline M & 35 & 7 & 28 & \\
\hline $\mathrm{F}$ & 39 & 5 & 34 & \\
\hline B-symptoms & & & & 0.016 \\
\hline No & 36 & 2 & 34 & \\
\hline Yes & 38 & 10 & 28 & \\
\hline Performance score & & & & 0.352 \\
\hline $0+1$ & 57 & 8 & 49 & \\
\hline $2-3$ & 17 & 4 & 13 & \\
\hline Stage & & & & 0.264 \\
\hline$|-| \mid$ & 7 & 0 & 7 & \\
\hline III-IV & 67 & 12 & 55 & \\
\hline Extranodal foci & & & & 0.074 \\
\hline No & 42 & 4 & 38 & \\
\hline Yes & 32 & 8 & 24 & \\
\hline Splenomegaly & & & & 0.044 \\
\hline No & 59 & 7 & 52 & \\
\hline Yes & 15 & 5 & 10 & \\
\hline $\begin{array}{l}\text { Bone marrow } \\
\text { involvement }\end{array}$ & & & & 0.028 \\
\hline No & 51 & 4 & 47 & \\
\hline Yes & 23 & 8 & 15 & \\
\hline S-LDH & & & & 0.296 \\
\hline Normal & 41 & 5 & 36 & \\
\hline Elevated & 33 & 7 & 26 & \\
\hline IPI score & & & & 0.018 \\
\hline $0-2$ & 21 & 0 & 21 & \\
\hline $3-5$ & 53 & 12 & 41 & \\
\hline \multicolumn{5}{|l|}{ Therapy response } \\
\hline$C R$ & 58 & 7 & 51 & 0.066 \\
\hline
\end{tabular}

Abbreviations: $M$ male, $F$ female, $S$ - $L D H$ serum lactate dehydrogenase, IPI International Prognostic Index, $C R$ complete remission

the biological significance of substitutions in introns, the NetGene2 software was employed [14].

\section{Methylation-specific PCR}

The bisulfite conversion of DNA samples was performed by means of the EZ DNA Methylation Kit (Zymo Research, USA). Three hundred to $500 \mathrm{ng}$ of DNA was used per reaction. Analysis of the methylation status of the TP53 promoter was carried out by methylation-specific PCR on bisulfite-converted DNA in two microtubes with primers specific to methylated and unmethylated alleles, in accordance with the method described above [15]. For methodological reasons, detection of the methylation status of the TP53 promoter was performed on tumor samples from 69 patients with DLBCL by the methylation-specific PCR method (Fig. 1).

\section{Microsatellite analysis}

Assessment of the loss of heterozygosity of TP53 was carried out at microsatellite locus D17S796 by a PCR method [16]. In this analysis, 24 pairs of samples of normal and tumorous tissue from patients with DLBCL were used (Fig. 2).

\section{Statistical analysis}

A comparison of type frequencies of nucleotide substitutions in TP53 in DLBCL between the examined sample of patients and data in the IARC TP53 mutation database was performed by statistical methods: Pearson's $X^{2}$ test and Fisher exact test. Clinical and laboratory features were compared using the Fisher exact test. Differences were considered statistically significant at $\mathrm{p}<0.05$.

\section{Results \\ Mutations in coding and intron sequences of the TP53 gene}

Overall, 33 mutations were revealed: 21 in coding and 12 in intron sequences of TP53 (Fig. 3). The following distribution of mutations was observed (Table 2): 1 (3\%) mutation causing a defect of RNA splicing, 11 (33\%) intron mutations with an unknown effect, 12 (37\%) missense mutations, 6 (18\%) sense mutations, 2 (6\%) nonsense mutations, and 1 (3\%) frameshift mutation in the TP53 gene. Except for A189Pfs, all these mutations (96.9\%) were single-nucleotide substitutions, 5 (15.6\%) of which were mutations of type $\mathrm{GC}>\mathrm{AT}$ in $\mathrm{CpG}$ islands. Substitutions GC > AT constituted 34.4\%, GC > CG 3.1\%, GC> TA 9.4\%, AT>GC 12.5\%, AT>CG 12.5\%, and $\mathrm{AT}>\mathrm{TA}$ substitutions represented 12.5\%; these

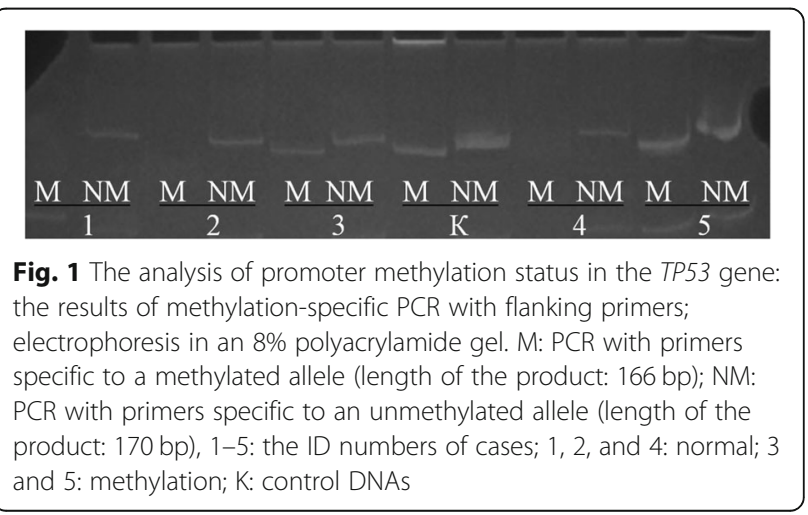




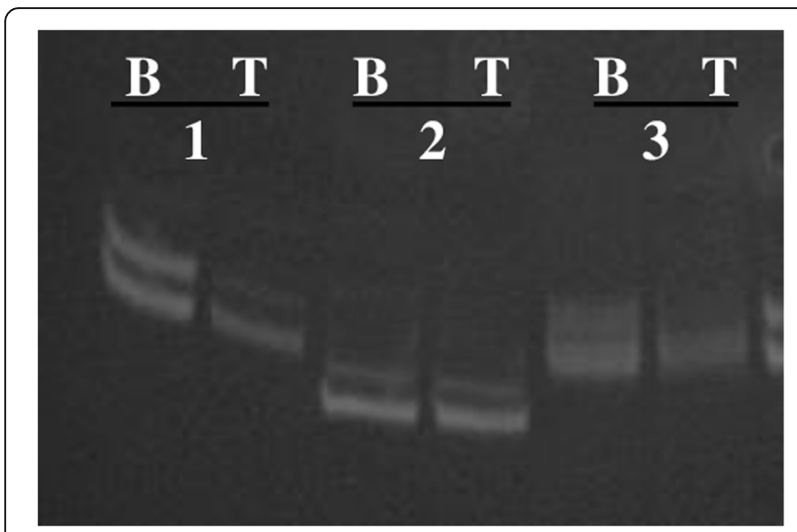

Fig. 2 The analysis of microsatellite instability in locus D175796: the results of PCR with flanking primers, electrophoresis in an $8 \%$ polyacrylamide gel (length of the product: 144-174 bp); B: DNA from blood, T: DNA of a tumor tissue, 1-3: the ID numbers of cases; 1, 3: loss of heterozygosity; 2: normal

results did not significantly differ from the data in the IARC TP53 mutation database (Fig. 2).

All mutations in the coding sequences of TP53 that were identified in our sample of patients with DLBCL had been described earlier in the IARC TP53 mutations database [11] in other oncological diseases, and these mutations (with the exception of p.A307A) are located in exons 5-8 coding for the DNA-binding domain p53. In the examined sample, $4(6.8 \%)$ patients had multiple mutations, and some findings were revealed repeatedly (each in two cases) (in coding sequences: p.W146R, p.T155I, p.V272E, and p.R213X; in intron regions: IVS7 $+31 \mathrm{G}>\mathrm{C}$, IVS $9+12 \mathrm{~T}>\mathrm{C}$, and IVS $8+10 \mathrm{C}>\mathrm{A}$; see Table 1).

Evaluation of biological significance of all the revealed missense mutations of TP53 in our patients with DLBCL yielded the following results (Table 3): All three prognostic software tools (PolyPhen-2, SIFT and Mut_ass) classified mutations p.L130F, p.T155I, p.R196Q, p.G244S, p.V272E, and p.A276V (which lead to appearance of a functionally inactive protein) as dangerous, probably pathogenic substitutions, or substitutions with a high/moderate degree of danger. In contrast, mutations p.W146R and p.G293R (slightly decreasing the activity of p53) and mutation p.R156C (hyperactive p53) were regarded as non-pathogenic, neutral substitutions or substitutions with a low/moderate degree of danger.

Undoubtedly, mutations p.R213X and p.A189Pfs have biological significance because each causes emergence of a nonfunctional truncated protein. It is more complicated to evaluate the effect of sense mutations detected in our sample of patients because such mutations are considered synonymous substitutions, i.e., keeping the sense of a codon. According to the prognosis of TP53 Mutant Assessor, among the sense mutations, substitution p.A307A is noteworthy because codon 307 is near the end of an exon and potentially may be located in a splicing site of an RNA molecule [17].

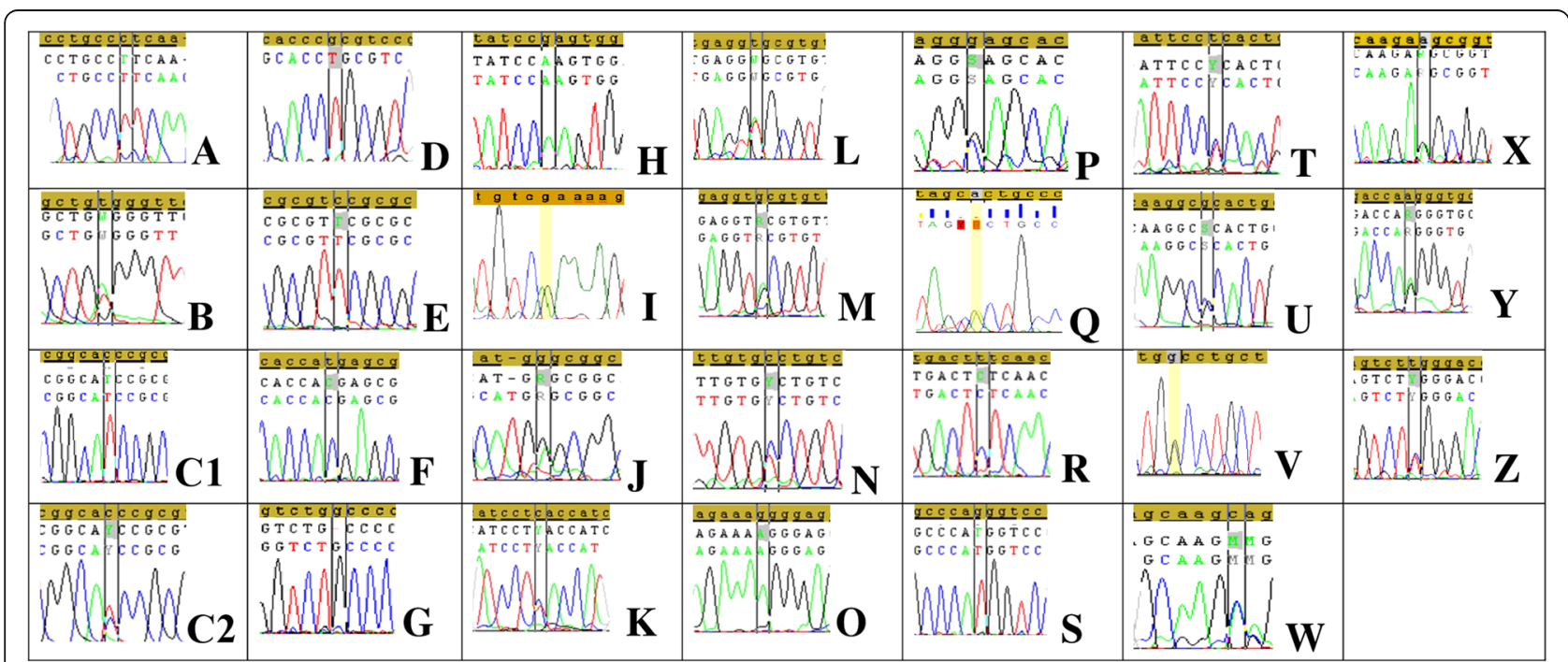

Fig. 3 The sequenced fragments of DNA containing mutations of TP53. a: homozygote of p.L130F, b: a heterozygote of p.W146R, c1: a homozygote of p.T155I, c2: a heterozygote of p.T155I, d: a homozygote of p.R156C, e: a homozygote of p.V157V, f: a homozygote of p.H179H, $\mathbf{g}$ : a homozygote of p.A189Pfs, $\mathbf{h}$ : a homozygote of p.R196Q, $\mathbf{i}$ : a heterozygote of p.R213X, j: a heterozygote of p.G244S, $\mathbf{k}$ : a heterozygote of p.L252 L, I: a heterozygote of p.V272E, $\mathbf{m}$ : a heterozygote of p.V272 V, $\mathbf{n}$ : a heterozygote of p.A276V; $\mathbf{o}$ : a homozygote of p.G293R, $\mathbf{p}$ : a heterozygote of p.G302G, q: a heterozygote of p.A307A, $\mathbf{r}$ : a homozygote of IVS4-30T > C, $\mathbf{s}$ : a homozygote of IVS5 + 43G > T, $\mathbf{t}$ : a heterozygote of IVS5-17T > C, $\mathbf{u}$ : a heterozygote of IVS6-36G > C, v: a heterozygote of IVS7 + 31G > C, w: a heterozygote of IVS8 + 10C > A, $\mathbf{x}$ : a heterozygote of IVS8 + 20A > G, $\mathbf{y}$ : a heterozygote of IVS8 $+37 \mathrm{~A}>\mathrm{G}$, and $\mathbf{z}$ : a heterozygote of IVS9 $+12 \mathrm{~T}>\mathrm{C}$ 
Table 2 General characteristics of sequencing results

\begin{tabular}{|c|c|c|c|c|c|}
\hline \multicolumn{2}{|l|}{ Intron mutations } & \multicolumn{4}{|c|}{ In coding sequence of TP53 gene } \\
\hline With unknown effect & Influence on splicing & Nonsense & Frame-shift mutations & Missense & Samesense \\
\hline IVS4-30T > C & & & & p.L130F & \\
\hline IVS5 + 43G > T & & & & p.W146R & \\
\hline IVS5-17T >C & & & & p.T155| & p.V157V \\
\hline IVS7 + 31G > C & & & & p.R156C & p.H179H \\
\hline IVS8 $+10 C>A^{a}$ & IVS6-36G > C & p.R213Xa & p.A189Pfs & p.R196Q & p.L252 L \\
\hline IVS8 + 20A > G & & & & p.G244S & p.V272 V \\
\hline IVS8 + 37A > G & & & & p.V272 $\mathrm{E}^{\mathrm{a}}$ & p.G302G \\
\hline IVS9 $+12 T>C^{a}$ & & & & p.A276V & p.A307A \\
\hline (rs1800899) & & & & p.G293R & \\
\hline
\end{tabular}

Note. ${ }^{\text {a }}$ Mutations occurring twice in the study population

The functional effects of the majority of intronic mutations revealed in our group of patients with DLBCL are unknown. One of the biologically significant mutations of the TP53 gene (IVS6-36G > C) is located in intron 6 of the gene. According to the TP53 UMD mutation database, in human cancer, this mutation means changes that influence splicing [11]. An in vitro experiment indicates that this substitution in the absence of a change in gene coding sequence leads to the survival of cells after chemotherapy and inhibits apoptosis for a long period [18]. According to NetGene2 prognosis, in the group of patients with DLBCL in our study, among the substitutions detected within introns, mutation IVS5 $+43 \mathrm{G}>\mathrm{T}$ caused formation of an additional acceptor site of splicing, which is absent under normal conditions. It may lead to inclusion of a part of intron 5 in the sequence of mRNA, premature formation of a stop codon at position 189, and the synthesis of a truncated p53 protein lacking functional activity. Besides, IVS4-30 $\mathrm{T}>\mathrm{C}$ is outstanding among intron mutations because the alternative gene promoter is placed in intron 4 of TP53. This promoter takes part in the synthesis of the delta133 isoform, which is expressed in lymphoid tissue under normal conditions [19].

Analysis of allelic imbalance and TP53 methylation status The frequency of TP53 promoter methylation in the sample of 69 patients with DLBCL was 4 (5.8\%). Promoter methylation frequency did not significantly differ in the subgroups with the mutant and wild-type gene sequence [1 (4.2\%) out of 24 vs $3(6.7 \%)$ out of $45, p=$ 0.5663).

Detection of the loss of heterozygosity of TP53 using microsatellite marker D17S796 was performed on tumor samples from 24 patients with DLBCL, among which 13 patients had mutations, and 11 patients did not have changes in TP53 sequence. Six (25\%) cases of loss of heterozygosity were revealed, among which 5 (83.3\%) cases of loss of heterozygosity were detected by the sequencing method in DLBCL tissue samples with mutations in

Table 3 The results of functional analysis of missense mutations of TP53

\begin{tabular}{|c|c|c|c|c|}
\hline \multirow[t]{2}{*}{ Mutation } & \multicolumn{3}{|l|}{ Functional prediction } & \multirow{2}{*}{$\begin{array}{l}\text { Activity of p53 protein in } \\
\text { experiment in vitro } \\
\text { [reference] }\end{array}$} \\
\hline & $\begin{array}{l}\text { PolyPhen-2 } \\
\text { (description of mutation) }\end{array}$ & $\begin{array}{l}\text { SIFT } \\
\text { (description of mutation) }\end{array}$ & $\begin{array}{l}\text { Mut_ass } \\
\text { (degree of pathogenicity) }\end{array}$ & \\
\hline p.L130F & Probably pathogenic & Dangerous & High & Not active [44] \\
\hline p.W146R & Non-pathogenic & Neutral & Low & Slightly reduced [44] \\
\hline p.T155। & Probably pathogenic & Dangerous & Moderate & Not active [44-46] \\
\hline p.R156C & Non-pathogenic & Neutral & Low & Hyperactive $[37,44]$ \\
\hline p.R196Q & Probably pathogenic & Dangerous & High & Not active [38] \\
\hline p.G244S & Probably pathogenic & Dangerous & Moderate & Not active $[39,45]$ \\
\hline p.V272E & Probably pathogenic & Dangerous & High & Not active [44] \\
\hline p.A276V & Probably pathogenic & Dangerous & Moderate & Not active [46] \\
\hline p.G293R & Non-pathogenic & Neutral & Moderate & Slightly reduced [44] \\
\hline p.A276V & Probably pathogenic & Dangerous & Moderate & Not active [38] \\
\hline p.G293R & Non-pathogenic & Neutral & Moderate & Slightly reduced [44] \\
\hline
\end{tabular}


exons 5-8 and adjacent intron regions of the TP53 gene. Gene promoter methylation was uncovered in one case of the loss of heterozygosity in a DLBCL tissue sample.

\section{TP53 mutation status and clinical features of DLBCL}

The study cohort was divided into two subgroups: with and without functional TP53 gene mutations (TP53mut and TP53wt, accordingly). The TP53mut subgroup comprised 12 patients: patients with p.L130F, p.T155I, p.A307A, p.R196Q, p.G244S, IVS6-36G >C and p.A276V mutations, two patients with p.R213X mutation, two patients with p.V272E mutation and one patient with multiple mutations (p.T155, p.A189Pfs and IVS5 $+43 G>T$ ). The clinical features of patient's subgroups are compared and summarized in Table 1. The analysis demonstrate that TP53mut correlated with B-symptoms $(P=0.016)$, splenomegaly $(P=0.044)$ and bone marrow involvement $(P=0.028)$, as well as IPI score of $>2(P=0.018)$.

DLBCL patients with TP53wt tended to had complete remission more often $(P=0.066$, Table 1$)$ and had better overall survival (OS) $(P=0.026$, Fig. 4) compared with DLBCL patients with TP53mut. The 5-year OS was 69.4\% for patients with TP53wt versus $41.7 \%$ for those with TP53mut DLBCL. The median OS of DLBCL patients with TP53mut was 20 months. In contrast, median OS of DLBCL patients with TP53wt was not achieved. Univariate analysis showed, that extranodal foci, IPI score of $>2$ and TP53 mutations predicted decrease OS of DLBCL patients. Multivariate analysis showed that IPI score were the only prognostic factors that independently predicted worse OS of DLBCL patients treated with R-CHOP and

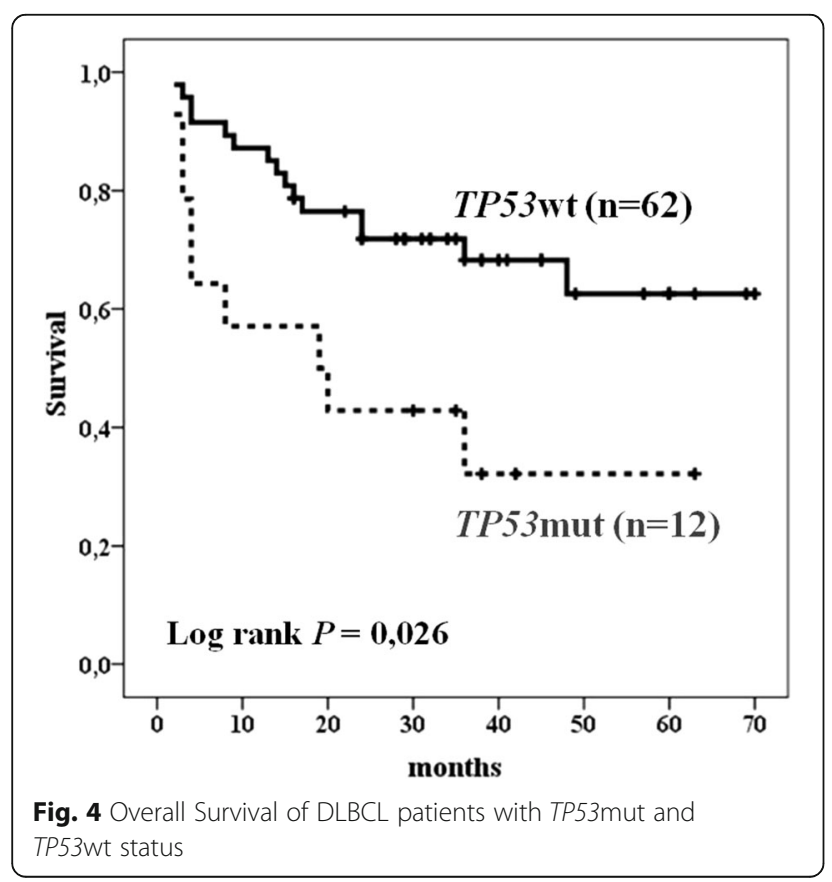

R-CHOP-like regiments. Patients with IPI score of $>2$ had a three times hazard for OS $(P=0.005)$ compared with patients with IPI score of $\leq 2$ (Table 4).

Because of the small cohort of DLBCL patients with other TP53 aberrations in our study, we do not present the analysis of prognostic and predictive impact of loss of heterozygosity and methylation.

\section{Discussion}

Analysis of literature data has shown that deletion of 17p13.1 leading to the loss of heterozygosity of TP53 has been registered at different frequencies in various studies: from 30.4 to $42 \%$ according to Chinese authors [2022], from 40 to $50.4 \%$ in the Czech population [23, 24], $30.4 \%$ in the Arab population [25], and $22.5 \%$ in the Austrian population [26]. The lowest frequency of $17 \mathrm{p} 13.1$ deletion (22.2\%) is reported in the International DLBCL Rituximab-CHOP Consortium Program Study [27], combining the samples of patients from 16 hematological centers in the USA, Switzerland, Holland, Germany, Italy, and Spain.

The most actively studied topic on TP53 gene variability in DLBCL is the analysis of its coding sequences revealing the presence of mutations. It has been shown that mutation frequency in the TP53 gene in DLBCL is $20 \%$ or higher [28].

In 1990, the IARC TP53 mutation database was created for documenting the mutations in this gene and contains information on more than 30,000 somatic and 700 germ-line mutations at present [24].Research in this database has revealed that in DLBCL, more than 120 mutations of TP53 have been described; 95\% of them are single-nucleotide substitutions: $88 \%$ are missense

Table 4 Univariate and multivariate analysis of OS predictors of patients with $\mathrm{DLBCL}$

\begin{tabular}{llll}
\hline & HR & $95 \% \mathrm{Cl}$ & $P$-value \\
\hline Univariate analysis & & & \\
$\quad$ B-symptoms & 2.401 & $0.530-0.876$ & 0.256 \\
Performance score 2-3 & 1.938 & $0.905-4.149$ & 0.088 \\
Stage III-IV & 2.025 & $0.576-7.116$ & 0.271 \\
Extranodal foci & 3.233 & $1.140-9.951$ & 0.029 \\
Bone marrow involvement & 1.539 & $0.501-4.722$ & 0.451 \\
Elevated S-LDH & 1.073 & $0.900-9.438$ & 0.068 \\
IPI score > 2 & 2.844 & $1.384-5.842$ & 0.004 \\
TP53mut & 2.707 & $1.077-6.800$ & 0.034 \\
Multivariate analysis & & & \\
IPI score > 2 & 2.994 & $1.405-6.381$ & 0.005 \\
TP53mut & 2.128 & $0.627-7.217$ & 0.226 \\
Extranodal foci & 2.405 & $0.787-7.369$ & 0.125 \\
\hline
\end{tabular}

Abbreviations: S-LDH serum lactate dehydrogenase, IPI International Prognostic Index, $H R$ hazard ratio, $\mathrm{Cl}$ confidence interval 
mutations, $7 \%$ are nonsense mutations, and $5 \%$ are frame-shift mutations. More than $95 \%$ of mutations have been detected in exons $5-8$, but mutations in exons 911 have not been described.

The following codons are hotspots of mutations in TP53 in relation to DLBCL (in the order of decreasing frequency): 248, 273, 175, 245, 281, 244, 305, 249, and 297 (http://p53.iarc.fr/DownloadDataset.aspx). Nonetheless, the prevalence of so-called hotspot mutations may change depending on the type of cancer and the ethnic origin of patients [29]. Comparative analysis of TP53 mutations indicates that their diversity and frequencies may significantly vary too, depending on the population under study [30]. There is no information about a Russian population in the current version of the IARC TP53 mutation database.

The vast majority of studies on the role of changes in the nucleotide sequence of TP53 have focused on exons $5-8$. The intron regions have hardly been researched. Nevertheless, these sequences may potentially influence not only splicing of RNA but also gene expression by disturbing the processing autoregulation, normal post-transcriptional mRNA modifications, and post-translational protein modifications [18, 31, 32].

The relation between hypermethylation of the TP53 promoter and downregulation of gene transcription has been revealed in some tumors [4, 33, 34]. Despite thorough exploration of this gene's methylation in cancer, this topic has been insufficiently studied in hematological cancers and hardly addressed in lymphoproliferative diseases [4]. For example, methylation of the TP53 promoter is observed in one-third of patients with acute lymphoblastic leukemia [35] and in one-fifth of patients with chronic lymphocytic leukemia [4]. There is only anecdotal evidence on the frequency of methylation of the TP53 promoter in DLBCL [36]. Comprehensive characterization of TP53 gene variability in DLBCL has not been carried out yet.

The aim of this study was to comprehensively describe the frequency of promoter methylation and that of loss of heterozygosity as well as the frequency, diversity, and functional significance of mutations in coding and intron regions of the TP53 gene among patients with DLBCL in Novosibirsk, Russia.

The diversity of single-nucleotide substitutions detected in tumor samples from our group of patients with DLBCL did not significantly differ from that in the IARC TP53 mutation database. Mutations in regions encoding the DNA-binding site were predominant (95\%). Mutation p.G293R is the only revealed missense substitution that does not affect the functionally significant DNA-binding domain of p53.

Searches in the IARC TP53 mutation database showed that all the functionally significant mutations detected in our study population had been described previously in a wide range of human cancers. Codons 196 and 213 in various cancers and codon 244 in hematological cancers in general and in DLBCL in particular are hotspots of mutations in TP53 (http://p53.iarc.fr/DownloadDataset.aspx).

Moreover, Li-Fraumeni syndrome (http://p53.iarc.fr/ DownloadDataset.aspx) has been described, which is characterized by the development of cancer in different parts of the body because of a germline mutation, p.R213X, p.G244S, p.L130F, or p.T155, similar to the mutations described in our study.

In this study, mutations were not detected in the majority of codons $(248,273,175,245,281,305,249$, and 297, except codon 244) for which most of the mutations in TP53 have been described in DLBCL in the IARC TP53 mutation database. Codons 275, 155, 272, and 212 were found to be hotspots of mutations in the analyzed sample of patients.

Review of the published literature [37-40] about the consequences of mutations in the TP53 gene showed that each of these mutations may have multidirectional effects on different functions of p53. These effects may be tentatively subdivided into the consequences for protein structure, its biochemical properties, and biological activity and, in some cases, lead to the emergence of new functions of p53, absent in the wild-type protein.

Thus, each of the mutant forms of the protein is a unique product of a mutation and may combine an increase and/or decrease in a particular type of p53 activity and may alter its structure or generate new properties.

The emergence of a functionally inactive protein $\mathrm{p} 53$ in the analyzed group of patients with DLBCL was caused by one of missense mutations-p.L130F, p.T155I, p.R196Q, p.G244S, p.V272E, or p.A276V - together with mutation p.A189Pfs, leading to frameshift mutations, nonsense substitution p.R213X, or splicing mutation IVS6-36G > C.

All the above events in the coding part of the genethat affect the sequence carrying information about highly conserved sites of the DNA-binding domain of p53-were fixed during evolution (in phylogeny) and occur in most isoforms of p53 and in the structure of homologous proteins p63 and p73.

Mutations p.R213X and p.G244S as well as p.V272E have already been described in DLBCL [41, 42], and p.T155I (detected in our study) has been previously detected in tumor samples from some patients with chronic lymphocytic leukemia and is known to be associated with poor prognosis and a weak response to treatment [43].

Among cases of hematological cancers, mutation p.V272E has been described in Burkitt's lymphoma, Hodgkin's lymphoma, and B-cell non-Hodgkin's lymphoma (http://p53.iarc.fr/DownloadDataset.aspx). 
All these findings are suggestive of selection of p.L130F, p.T155I, p.R196Q, p.G244S, p.V272E, p.A276V, p.R213X, and p.A189Pfs at various stages of cancer progression [37-39, 44-46]; therefore, their detection in tumor samples from patients with DLBCL is not coincidental.

Our findings indicate that only two missense substitutions (p.W146R and p.G293R) - among all the revealed cases in the analyzed group of patients with DLBCLdid not significantly influence the function of p53. In contrast, p.R156C led to the appearance of a hyperactive mutant protein.

Out of all the mutations detected in our study, only two may influence splicing of RNA. These include samesense substitutions p.A307A and IVS6-36G $>$ C. The functional significance of IVS6-36G $>C$ has been proved in an in vitro experiment [18]. According to the prediction of TP53 Mutant assessor (release 1.00, 2012), p.A307A is also located at a splicing site of RNA [17]. Even though in sense mutations, the new codon continues encoding the same amino acid, it is believed that this type of mutations may change splicing, transcription, and/or stability of RNA [11].

The functional effects of most intron and sense mutations detected in our group of patients with DLBCL (but not discussed) remain unknown. It is likely that intron mutations may influence not only RNA splicing but also gene expression control, by causing gain- or loss-of-function regulatory elements in TP53 region, thereby creating or disrupting binding sites for certain DNA-sequence-specific transcription factors that interfere with normal activation or autoregulation of TP53, and possibly transcriptional regulation of other potential downstream genes [31, 47]. Furthermore, intron mutation IVS4-30 T $>C$ is noteworthy because an alternative gene promoter is placed in intron 4 of TP53 and takes part in the synthesis of delta133 and delta160 isoforms of p53 [19]. Thus, whether these newly identified intron mutations of TP53 are functional warrants further investigation.

Some published reports about low frequencies of TP53 promoter methylation in DLBCL were verified in our group of patients. The frequency of TP53 promoter methylation in the analyzed group of patients with DLBCL was $5.8 \%$ and did not differ significantly from subgroups with mutant (4.2\%) and wild-type (6.7\%) gene structure or from the findings of K. Amara and coauthors (3.7\%) [36].

Analysis of the loss of heterozygosity of TP53 was performed on 24 tumor samples of DLBCL in our study population, and 13 of them were found to have mutations, whereas 11 did not have changes in the sequences of TP53. Our investigation of microsatellite marker D17S796, which is located near TP53, detected 6 (25\%) cases of loss of heterozygosity, in agreement with the literature data [27].

Furthermore, loss of heterozygosity was observed only in the subgroup of patients with a alteration of the TP53 gene (mutations were revealed in 5 tumor samples, and promoter methylation in one tumor), which accounted for $6(42.9 \%)$ out of 14 versus $0 \%$ in the group of $10 \mathrm{pa}$ tients with the intact gene $(p=0.0223)$.

Our comprehensive assessment of gene variability indicates that the dysfunction of p53 in DLBCL may emerge via a two-hit mechanism. According to this model, two sequential events are necessary for transformation of a normal B cell into a cancerous cell during carcinogenesis of at least some cases of DLBCL. The first event is a mutation or methylation in the TP53 promoter, giving rise to a cell with increased risk of malignant transformation. The second event is the loss of an intact allele of TP53 in the cell; this change is necessary for tumorigenesis.

Thus, in DLBCL, our results proved the selection of functionally significant mutations in the gene regions encoding the DNA-binding domain of p53.

In the analyzed sample of patients with DLBCL, the location of hotspots of mutations (in contrast to the set of single-nucleotide substitutions) is different from the data listed in the IARC TP53 Mutation database.

The presence of important intronic and samesense substitutions was demonstrated and confirmed the importance of studying the noncoding gene regions adjacent to exons and of bioinformatic analysis of the uncovered synonymous substitutions. In total, our results show that TP53 mutation status is a prognostic factor that stratifies DLBCL patients treated with R-CHOP and $\mathrm{R}$-CHOP-like regimens. This observation is a further supports the crucial role of p53 in death of tumor cells and tumor suppression. In Russian cohort of de novo DLBCL patients, we show that TP53mut are correlated with B-symptoms, splenomegaly and bone marrow involvement, as well as adverse IPI prognostic groups. Nonetheless, DLBCL patients with TP53wt tended to had complete remission more often $(P=0.066)$.

It is known, that despite the addition of rituximab to therapy, TP53 mutation is an independent prognostic factor that predicts poor survival in patients with DLBCL [28]. To eliminate the possible impact of TP53mut on OS, we also performed survival analysis for patients study cohort and found that patients with TP53wt had significantly better OS $(P=0.026)$. These data are in agreement with a recent study [27].

Our results show that together with extranodal foci and IPI score of $>2$ TP53mut predicted decrease OS of DLBCL patients. In fact, TP53 mutation status is an independent prognostic factor in patients with DLBCL treated with R-CHOP [28]. But multivariate analysis 
show that the impact on survival DLBCL patients of IPI score of $>2$ is more pronounced than the impact of TP53mut. This might be because of the small cohort of DLBCL patients with TP53mut in our study.

\section{Conclusions}

In conclusion, in the present study, we identified TP53 mutation patterns in a Russian cohort of patients with de novo DLBCL who were treated with R-CHOP and R-CHOP-like regimens and confirmed that TP53 mutation status is a valuable prognostic biomarker. Therefore, therapeutic approaches targeting the inactivated TP53 pathway may further improve clinical outcomes of patients with DLBCL.

Because of the small cohort of DLBCL patients with other TP53 aberrations in our study we do not present the analysis of prognostic and predictive impact of $\mathrm{LOH}$ and methylation. However, the comprehensive analysis of TP53 status gives us better insights into the possible mechanisms behind participation of this gene's variability in the pathogenesis of DLBCL. It was shown here that dysfunction of p53 in DLBCL may emerge according to the two-hit principle.

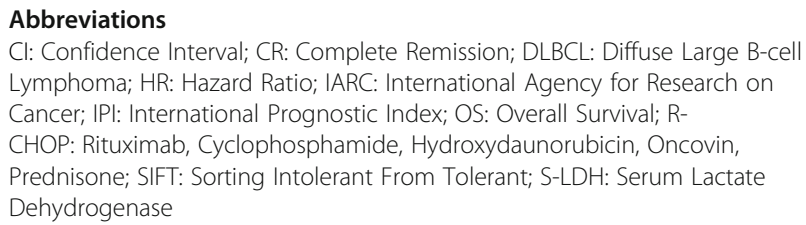

\section{Acknowledgements}

We ate grateful to BGRSISB Organizing Committee and to the reviewers for valuable comments.

\section{Funding}

The publication cost was covered by Russian Ministry of Education and Science Project No.28.12487.2018/12.1. The study was supported by Budgetary Project No.0541-2014-0002. YLO was supported by ICG SB RAS budget project 0324-2019-0040.

\section{Availability of data and materials}

All data generated or analysed during this study are included in this published article [and its supplementary information files].

\section{About this supplement}

This article has been published as part of BMC Medical Genomics Volume 12 Supplement 2, 2019: Selected articles from BGRSISB-2018: medical genomics. The full contents of the supplement are available online at https:// bmcmedgenomics.biomedcentral.com/articles/supplements/volume-12supplement-2.

\section{Authors' contributions}

ENV - performed analysis and data interpretation and was a major contributor in writing the manuscript. TIP - supervised research. MIV supervised research. VNM - performed genetic testing. YLO - performed statistical analysis. OBS - collected the patients data. All the authors read and approved the final manuscript.

\section{Ethics approval and consent to participate}

The study was approved by the Local Ethics Committee of Novosibirsk State Medical University. All participating patients signed an informed consent form before the study started.
Consent for publication

Not applicable.

\section{Competing interests}

The authors declare that they have no competing interests.

\section{Publisher's Note}

Springer Nature remains neutral with regard to jurisdictional claims in published maps and institutional affiliations.

\section{Author details}

${ }^{1}$ Institute of Internal and Preventive Medicine, Branch of Institute of Cytology and Genetics, Siberian Branch of Russian Academy of Sciences, Novosibirsk, Russia. ${ }^{2}$ Novosibirsk State Medical University, Novosibirsk, Russia. ${ }^{3}$ Novosibirsk State University, Novosibirsk, Russia.

Published: 13 March 2019

\section{References}

1. Swerdlow S.H., Campo E., Harris N.L., Jaffe E.S., Pileri S.A., Stain H., et al. WHO classification of tumors of Haematopoetic and lymphoid tissues. Lyon; 2008.

2. Niroula R, Butera J. Genetics and diffuse large B-cell lymphoma. R I Med J. 2015;98(11):23-6.

3. Skibola CF, Curry JD, Nieters A. Genetic susceptibility to lymphoma. Haematologica. 2007:92(7):960-9.

4. Xu-Monette ZY, Medeiros L, Li Y, Orlowski RZ, Andreeff M, Bueso-Ramos CE, et al. Dysfunction of the TP53 tumor suppressor gene in lymphoid malignancies. Blood. 2012;119(16):3668-83. https://doi.org/10.1182/blood2011-11-366062

5. Hollstein M, Hainaut P. Massively regulated genes: the example of TP53. J Pathol. 2010;220(2):164-17. https://doi.org/10.1002/path.2637.

6. Cheung K, Horsman DE, Gascoyne RD. The significance of TP53 in lymphoid malignancies: mutation prevalence, regulation, prognostic impact and potential as a therapeutic target. Br J Haematol. 2009;146(3):257-69. https://doi.org/10.1111/j.1365-2141.2009.07739.x.

7. Gudkov AV, Komarova EA. The role of p53 in determining sensitivity to radiotherapy. Nat Rev Cancer. 2003;3(2):117-29.

8. Peller S, Rotter V. TP53 in hematological cancer: low incidence of mutations with significant clinical relevance. Hum Mutat. 2003;21(3):277-84.

9. Kopnin B.P., Kopnin P.B., Khromova N.V., Agapova L.S. Multifaced p53: variety of forms, functions, tumor-supressive and oncogenic activities. Clinical Oncohematology. Basic Research and Clinical Practice. Russian Journal (Klinicheskaya onkogematologiya). 2008; 1(1): 2--9. (in Engl.)

10. http://p53.iarc.fr/download/tp53_directsequencing_iarc.pdf (access date 31/ 01/2019).

11. Edlund K, Larsson O, Ameur A, Bunikis I, Gyllensten U, Leroy B, et al. Datadriven unbiased curation of the TP53 tumor suppressor gene mutation database and validation by ultradeep sequencing of human tumors. Proc Natl Acad Sci U S A. 2012;109(24):9551-6.

12. Petitjean A, Mathe E, Kato S, Ishioka C, Tavtigian SV, Hainaut $P$, et al. Impact of mutant p53 functional properties on TP53 mutation patterns and tumor phenotype: lessons from recent developments in the IARC TP53 database. Hum Mutat. 2007;28(6):622-9.

13. Adzhubei I., Jordan D.M., Sunyaev S.R. Predicting functional effect of human missense mutations using PolyPhen-2. Curr Protoc Hum Genet. 2013; Ch.7: Unit 7.20. doi: https://doi.org/10.1002/0471142905.hg0720s76.

14. Brunak S, Engelbrecht J, Knudsen S. Prediction of human mRNA donor and acceptor sites from the DNA sequence. J Mol Biol. 1991;220(1):49-65.

15. Almeida LO, Custódio AC, Pinto GR, Santos MJ, Almeida JR, Clara CA, et al. Polymorphisms and DNA methylation of gene TP53 associated with extraaxial brain tumors. Genet Mol Res. 2009:8(1):8-18.

16. Grebe SK, Mclver B, Hay ID, Wu PS, Maciel LM, Drabkin HA, et al. Frequent loss of heterozygosity on chromosomes $3 p$ and $17 p$ without VHL or p53 mutations suggests involvement of unidentified tumor suppressor genes in follicular thyroid carcinoma. J Clin Endocrinol Metab. 1997;82(11):3684-91.

17. Leroy B, Fournier JL, Ishioka C, Monti P, Inga A, Fronza G, Soussi T. The TP53 website: an integrative resource Centre for the TP53 mutation database and TP53 mutant analysis. Nucleic Acids Res. 2013:41(Database issue):D962-9. https://doi.org/10.1093/nar/gks1033. 
18. Lehman TA, Haffty BG, Carbone CJ, Bishop LR, Gumbs AA, Krishnan S, et al. Elevated frequency and functional activity of a specific germ-line p53 intron mutation in familial breast cancer. Cancer Res. 2000;60(4):1062-9.

19. Mondal AM, Horikawa I, Pine SR, Fujita K, Morgan KM, Vera E, Mazur SJ, Appella E, Vojtesek B, Blasco MA, Lane DP, Harris CC. p53 isoforms regulate aging- and tumor-associated replicative senescence in T lymphocytes. J Clin Invest. 2013;123(12):5247-57.

20. Lu JT, Cen L, Zhou M. Prognostic value of P53 aberrations in diffuse large Bcell lymphoma. Zhongguo Shi Yan Xue Ye Xue Za Zhi. 2012;20(1):100-2.

21. Sun GX, Cao XS, Li Q, Wang ZL. Correlation of BCL-6, MYC and p53 gene abnormalities with immunological subtypes andprognosis of diffuse large B-cell lymphoma. Zhonghua Yi Xue Yi Chuan Xue Za Zhi. 2012;29(5):576-81.

22. Gao P, Li Q, Wang Z, Yan F, Lu C, Cao X. Significance of BCL-6, MYC, P53 genes abnormalities for the prognosis of diffuse large B-cell lymphoma. Zhonghua Yi Xue Yi Chuan Xue Za Zhi. 2014;31(5):628-31. https://doi.org/ 10.3760/cma.j.issn.1003-9406.2014.01.020.

23. Stefancikova L, Moulis M, Fabian P, Vasova I, Zedek F, Ravcukova B, et al. Prognostic impact of p53 aberrations for R-CHOP-treated patients with diffuse large B-cell lymphoma. Int J Oncol. 2011;39(6):1413-20.

24. Stocklein H, Smardova J, Macak J, Katzenberger T, Holler S, Wessendorf S, et al. Detailed mapping of chromosome 17p deletions reveals $\mathrm{HIC1}$ as a novel tumor suppressor gene candidate telomeric to TP53 in difuse large Bcell lymphoma. Oncogene. 2008;27(18):2613-25.

25. Tamimi Y, Al-Harthy S, Al-Haddabi I, Al-Kindi M, Babiker H, Al-Moundhri M, Burney I. The p53 mutation/deletion profle in a small cohort of the Oman population with diffuse large B-cell lymphoma. Sultan Qaboos Univ Med J. 2014;14(1):e50-8.

26. Simonitsch-Klupp I, Hauser I, Ott G, Drach J, Ackermann J, Kaufmann J, et al. Diffuse large B-cell lymphomas with plasmablastic/plasmacytoid features are associated with TP53 deletions and poor clinical outcome. Leukemia. 2004; 18(1):146-55.

27. Xu-Monette ZY, Wu L, Visco C, Tai YC, Tzankov A, Liu WM, et al. Mutational profile and prognostic significance of TP53 in diffuse large B-cell lymphoma patients treated with R-CHOP: report from an international DLBCL rituximab-CHOP consortium program study. Blood. 2012;120(19):3986-96.

28. Young KH, Leroy K, Møller MB, Colleoni GW, Sánchez-Beato M, Kerbauy FR, Haioun C, et al. Structural profiles of TP53 gene mutations predict clinical outcome in diffuse large B-cell lymphoma: an international collaborative study. Blood. 2008;112(8):3088-98.

29. Frebourg T, Barbier N, Kassel J, Ng YS, Romero P, Friend SH. A functional screen for germ line p53 mutations based on transcriptional activation. Cancer Res. 1992:52(24):6976-8.

30. Tennis M, Krishnan S, Bonner M, Ambrosone CB, Vena JE, Moysich K, et al. p53 mutation analysis in breast tumors by a DNA microarray method. Cancer Epidemiol Biomark Prev. 2006;15(1):80-5

31. Glick BR, Pasternak JJ. Eds. Moleculer biotechnology. Principles and applications of recombinant DNA. 2nd ed. Washington: ASM Press; 1994.

32. Agirre X, Novo FJ, Calasanz MJ, Larrayoz MJ, Lahortiga I, Valganon M, et al. TP53 is frequently altered by methylation, mutation, and/or deletion in acute lymphoblastic leukaemia. Mol Carcinog. 2003;38(4):201-8.

33. Pogribny IP, James SJ. Reduction of p53 gene expression in human primary hepatocellular carcinoma is associated with promoter region methylation without coding region mutation. Cancer Lett. 2002;176(2):169-74.

34. Kang JH, Kim SJ, Noh DY, Park IA, Choe KJ, Yoo OJ, Kang HS. Methylation in the p53 promoter is a supplementary route to breast carcinogenesis: correlation between $\mathrm{CpG}$ methylation in the p53 promoter and the mutation of the p53 gene in the progression from ductal carcinoma in situ to invasive ductal carcinoma. Lab Investig. 2001;81(4):573-9.

35. Garcia-Delgado M, Larrayoz MJ, Novo FJ. Methylation of CpG dinucleotides and/or CCWGG motifs at the promoter of TP53 correlates with decreased gene expression in a subset of acute lymphoblastic leukemia patients. Oncogene. 2003;22(7):1070-2.

36. Amara K, Trimeche M, Ziadi S, Laatiri A, Hachana M, Sriha B, et al. Presence of simian virus 40 DNA sequences in diffuse large B-cell lymphomas in Tunisia correlates with aberrant promoter hypermethylation of multiple tumor suppressor genes. Int J Cancer. 2007;121(12):2693-702.

37. Kakudo Y, Shibata H, Otsuka K, Kato S, Ishioka C. Lack of correlation between p53-dependent transcriptional activity and the ability to induce apoptosis among 179 mutant p53s. Cancer Res. 2005;65(6):2108-14.
38. Monti P, Campomenosi P, Ciribilli Y, lannone R, Aprile A, Inga A, et al. Characterization of the p53 mutants ability to inhibit p73 beta transactivation using a yeast-based functional assay. Oncogene. 2003;22(34):5252-60.

39. Dearth LR, Qian H, Wang T, Baroni TE, Zeng J, Chen SW, et al. Inactive fullleng the p53 mutants lacking dominant wild-type p53 inhibition highlight loss of heterozygosity as an important aspect of p53 status in human cancers. Carcinogenesis. 2007;28(2):289-98.

40. Dekairelle AF, Tombal B, Cosyns JP, Gala JL. Assessment of the transcriptional activity of p53 improves the prediction of recurrence in superficial transitional cell carcinoma of the bladder. Clin Cancer Res. 2005;11(13):4724-32.

41. Young KH, Weisenburger DD, Dave BJ, Smith L, Sanger W, lqbal J, et al. Mutations in the DNA-binding codons of TP53, which are associated with decreased expression of TRAIL receptor-2, predict for poor survival in diffuse large B-cell lymphoma. Blood. 2007;110(13):4396-405.

42. Stefancikova L, Moulis M, Fabian P, Ravcukova B, Vasova I, Muzik J, Malcikova J, Falkova I, Slovackova J, Smardova J. Loss of the p53 tumor suppressor activity is associated with negative prognosis of mantle cell lymphoma. Int J Oncol. 2010;36(3):699-706.

43. Zenz T, Eichhorst B, Busch R, Denzel T, Habe S, Winkler D, et al. TP53 mutation and survival in chronic lymphocytic leukemia. J Clin Oncol. 2010; 28(29):4473-9.

44. Shiraishi K, Kato S, Han SY, Liu W, Otsuka K, Sakayori M, et al. Isolation of temperature-sensitive p53 mutations from a comprehensive missense mutation library. J Biol Chem. 2004;279(1):348-55.

45. Monti P, Campomenosi P, Ciribilli Y, lannone R, Inga A, Abbondandolo A, et al. Tumour p53 mutations exhibit promoter selective dominance over wild type p53. Oncogene. 2002;21(11):1641-8.

46. Campomenosi P, Monti P, Aprile A, Abbondandolo A, Frebourg T, Gold B, et al. P53 mutants can often transactivate promoters containin gap21 but not Bax or PIG3 responsive elements. Oncogene. 2001;20(27):3573-9.

47. Gao P, Xia JH, Sipeky C, Dong XM, Zhang Q, Yang Y, et al. Biology and clinical implications of the $19 q 13$ aggressive prostate cancer susceptibility locus. Cell. 2018;174(3):576-589.e18.

Ready to submit your research? Choose BMC and benefit from:

- fast, convenient online submission

- thorough peer review by experienced researchers in your field

- rapid publication on acceptance

- support for research data, including large and complex data types

- gold Open Access which fosters wider collaboration and increased citations

- maximum visibility for your research: over $100 \mathrm{M}$ website views per year

At $\mathrm{BMC}$, research is always in progress.

Learn more biomedcentral.com/submissions 